\title{
Vorwort zur fünfzehnten nnd sechzehnten Auflage
}

Die 15. und 16. Auflage des Dornblüth schen Wörterbuches muB ohne das Vorwort ihres Bearbeiters hinausgehen:

Dr. med. Emil Bannwarth

geboren den 10. Oktober 1862 in Mannheim

ist wenige Tage vor ihrer Vollendung, am 18. April 1929, in Berlin plötzlich gestorben. Dem kenntnisreichen Arzte, dem unverdrossenen Arbeiter, dem wackeren Kämpfer an dieser Stelle ein Wort der Erinnerung zu widmen, ist Ehrenpflicht. Emil Bannwarth hat seine medizinische Laufbahn 1888 als Dozent für Anatomie in Bern begonnen und 1894 als praktischer Arzt - zuerst in einem kleinen badischen Orte und dann (1908) in einem weiteren Wirkungskreise in Ägypten - fortgesetzt. Der Beginn des Weltkrieges sah den 52 jäbrigen ungerufen in der Heimat und bald als Bataillonsarzt an den verschiedensten Fronten. Durch den FriedensschluB jeder Möglichkeit beraubt, nach Kairo und in seine gute ärztliche Praxis zurückzukehren, diente er zunächst noch bis 1922 im Lazarett Kolberg, um sodann in kaufmännischer Stellung und zuletzt (von 1925 ab) als wissenschaftlicher Hilfsarbeiter im Zoologischen Museum Berlin noch ein bescheidenes Brot zu finden.

Was er als Anatom gearbeitet hat - er war auf diesem Felde Forscher, Maler und Bildhauer zugleich - bat lebhafte Anerkennung in den Fachkreisen gefunden, was er als Arzt gewesen ist, muB - nach den Erfolgen zu urteilen - auf bemerkenswerter Höhe gestanden haben, was er aber als Zoologe in der Erforschung des Korallenriffes von Suez geleistet hat, das ist, wie allein schon seine plastischen Arbeiten im Berliner Zoologischen Museum beweisen, schlechthin meisterlich gewesen.

Als Mensch war er ein Ritter ohne Furcht und Tadel, und wenn wir ihn zuweilen den geborenen Condottiere nannten, so zeugt das für die ungeweckten Energien, die wir dem rastlos tätigen und erfindungsreichen erdverbundenen Manne zutrauen durften.

In der vorliegenden Auflage sind wohl nur ganz wenige Artikel ohne die bessernde Hand Bannwarths geblieben. Entbehrliches hat er rücksichtslos gestrichen und damit aufs neue Platz für neue Beiträge gewonnen. Diese Einfügungen betreffen unter anderem neue biologische Grundbegriffe, wie die von LangeEichbaum, chemische Verfahrensweisen, mit deren Anwendung er grundlichst vertraut war, sowie die Hafflkrankheit und die Gebiete der Röntgenologie.

Berlin, den 29. April 1929.

Prof. Dr. Thilo Krumbach. 